\title{
Racial and Socioeconomic Disparities in
}

Percutaneous Endoscopic Gastrostomy (PEG) Tube Placement among elderly patients with dementia in the United States from the National inpatient

\section{sample}

Tanureet Kochar ( $\square$ tanureet.kochar89@outlook.com )

Detroit Medical Center https://orcid.org/0000-0001-9504-859X

Ashraf Abugroun

Detroit Medical Center

Asma Nayyar

Detroit Medical Center

Manar Abdel- Rahman

Qatar University

Pragnesh J Patel

Detroit Medical Center

Research article

Keywords: percutaneous endoscopic gastrostomy, dementia, racial, socio-economic disparities

Posted Date: May 20th, 2020

DOl: https://doi.org/10.21203/rs.3.rs-28267/v1

License: (c) (1) This work is licensed under a Creative Commons Attribution 4.0 International License.

Read Full License 


\section{Abstract \\ Background}

Placement of percutaneous endoscopic gastrostomy (PEG) tube in patients of advanced dementia has not been shown to improve nutritional status or mortality. The objective is to assess racial and socioeconomic disparities for PEG tube placement from National Inpatient Sample.

\section{Methods}

In a cross-sectional study, the National inpatient sample (NIS) registry was queried for all patients aged $\geq$ 70 who were diagnosed with dementia during the year 2016. Patients with dementia were identified using the Tenth revision (ICD-10) codes (F0150, F0151, F0280, F0281, F0390, F0391, G300, G301, G308, G309, G3109, G3183). Patients who received PEG tube were identified using ICD-10 diagnosis codes (Z431). Multivariable logistic regression models were utilized to determine the likelihood of PEG tube placement with adjustment for Patients demographics, socioeconomic factors, degree of frailty and comorbidities.

\section{Results}

Out of 1,745,028 patients with dementia, 35,075 patients had PEG tube placed. Majority of patients who received PEG tube were females (54.8\%), of white race (45.5\%) with a mean age of 82.3 years (SEM 0.02). Compared to controls, those who had PEG tube placement were more frail, had higher prevalence of chronic lung disease, diabetes, stroke, psychosis and nutritional deficiency anemias. On multivariable analysis, higher risk for PEG tube placement was seen in African Americans and Hispanics compared to Caucasians with a-OR 3.76 [95\%Cl: 3.47-4.07], $\mathrm{p}<0.001$ and 2.59 [95\% Cl:2.33-2.88], $\mathrm{p}<0.001$ respectively. A higher risk was also seen in patients with low income with a-OR 1.1(95\%Cl: 1.04-1.19), $p$ $=0.002$ and among those having Medicaid compared to Medicare insurance with a-OR 1.53 [95\% Cl: 1.30-1.80], $p<0.001$. Compared to males, females were found to have low chances for PEG tube placement with a-OR: 0.78 [95\%CO:0.74-0.82], p< 0.001. Hospital ownership, bed size and teaching status were found to have no impact on PEG tube utilization.

\section{Conclusion}

Despite the evidence against placement of PEG tubes in dementia patients, our findings confirm that PEG tubes are still being placed in frail and demented elderly. Apart from these, elderly patients with low income, African American origin and Medicaid enrollees have higher incidence of PEG tube placements. Efforts are needed to educate clinicians and community about worse outcomes of PEG tube placement in advanced dementia. 


\section{Background}

The prevalence of dementia is increasing across the globe as well as in United States. As per the Alzheimer's association 2018, there were approximately 5.7 million people living with dementia in the USA in year 2018 which is expected to increase to 13.8 million by 2050.The prevalence of dementia is estimated to double every 5 years after the age of 65 years, and at the age of 85 years, the prevalence is estimated to be approximately $50 \%{ }^{[1,2]}$.

Dementia leads to progressive loss of memory, communication and activities of daily living. The later stages of dementia are characterized by behavioral symptoms and severe loss of independence. Another characteristic feature of advanced dementia is dysphagia and loss of interest in eating ${ }^{[3]}$; which leads to increased stress amongst caregivers and family members regarding the nutritional status of the patient and ultimately leading to an alternative source of feeding in elderly patients. Therefore, enteral means of providing nutrition in form of nasogastric tube or PEG tube for adequate nutrition and hydration are taken into consideration. In a study published in 2009 named as the Choices, Attitudes, and Strategies for Care of Advanced Dementia at the End-of-Life (CASCADE) which followed individuals with advanced dementia over 18 months and concluded that more than $85 \%$ of the study cohort experienced eating difficulties with subsequent 6 -month mortality approaching $50 \%{ }^{[4]}$.

According to studies, placement of PEG tube in patients with advanced dementia not only leads to immediate post procedural complications but also does not significantly improve nutritional status, rates of re-hospitalization and short- or long-term mortality $[5,6,7,8,9,10]$. In compliance to choose wisely campaign launched by the American Board of Internal Medicine Physicians (ABIM), the American Geriatric Society (AGS) made an evidence-based recommendation in 2013 which stated, "Don't recommend percutaneous feeding tubes in patients with advanced dementia; instead offer oral assisted feeding" ${ }^{[11,12]}$. In our retrospective study, we analyzed the racial and socio-economic disparities among different ethnic groups regarding the PEG tube placement. We also assessed the impact of hospital factors such as hospital ownership and teaching status on the rates of PEG tube placements.

\section{Methods}

\section{Data Source}

This study is conducted using The National Inpatient Sample (NIS) of the Health Care Utilization Project (HCUP) sponsored by the Agency for Healthcare Research and Quality (AHRQ). The NIS is the largest allpayer inpatient database in the United States. The database represents a random selection of $20 \%$ sample of all inpatient hospitalizations. Data from approximately 7 million hospital stays with a weighted estimate of more than 35 million hospitalizations annually is included in the registry. Details on the design and structure of the NIS registry is available at http://www.hcup-us.ahrq.gov. NIS data is publicly available, contains no personal identifying information, accordingly institutional review board approval is not required. 


\section{Study population}

The NIS registry was queried for all adult patients aged above 70 who were diagnosed with dementia during the year 2016. Patients with dementia were identified using the Tenth revision (ICD-10) codes F0150, F0151, F0280, F0281, F0390, F0391, G300, G301, G308, G309, G3109, G3183. Patient who received gastrotomy tube were identified using ICD-10 diagnosis codes (Z431).

\section{Study variables and objectives}

Primary payers were classified into Medicare, Medicaid, private insurance, or self-pay. Household income was estimated based on the median income of the patient's ZIP code. A hospital is considered a teaching hospital if it has one or more Accreditation Council for Graduate Medical Education approved residency program, is a member of the Council of Teaching Hospitals (COTH) or has a ratio of full-time equivalent interns and residents to beds of .25 or higher. The hospital's location and teaching status were defined based on the AHA Annual Survey of Hospitals. A metropolitan statistical area is considered urban, and a non-metropolitan statistical area is regarded as rural. Teaching hospitals have an AMA-approved residency program or have membership in the Council of Teaching Hospitals.

The primary objective of the study is placement of a PEG tube. Variables of interest are race, insurance type, household income, hospital characteristics including hospital bed-size, teaching status and ownership.

\section{Statistical Analysis}

To account for the complex survey design, data was analyzed considering stratification, probability sampling, discharge weights, as well as robust variance estimation of all multivariable models as outlined by HCUP NIS analytic guidelines. National estimates for elderly patients with dementia were generated accordingly. Patient demographics, hospital factors and comorbidities were summarized as the mean and percentage with $95 \%$ confidence interval $(\mathrm{Cl})$ for continuous and categorical variables, respectively. Univariate logistic regression was performed to determine the unadjusted association of PEG tube placement with gender, race, primary insurance payer status, median household income per zip code and hospital factors including region, bed size, location and teaching status as well as ownership of the hospital. Degree of frailty was measured using ICD-10 frailty index which was previously validated. Multivariable models were adjusted for age, gender, insurance type, income, hospital characteristics, frailty index, DNI status and comorbidities. Adjusted OR for binary outcomes was reported together with their $95 \%$ confidence intervals. As the variables including age, race, gender, income and hospital teaching status had low rates of being missed ( $4.7 \%$ in total and $4 \%$ in patients who received PEG tube), no adjustment for missing values was indicated. All analyses were performed using STATA 15 (Stata Corp), a p-value $<0.05$ was considered significant. 


\section{Results}

Out of 1,745,028 enrolled patients, 35,075 had PEG tube placed. The median age was 82.3 (95\%Cl: $82.1-$ 82.5) years. Among those who got PEG tube placed, $54.8 \%$ were females. A total of $45.5 \%$ where of white race and $36 \%$ had low income. Majority of patients were Medicare insured (91.2\%), those hospitalized in large hospitals (50\%) that were urban teaching $(60.3 \%)$ with private-nonprofit ownership $(69.7 \%)$.

Compared to the control group, the rate of PEG tube placement was found to be higher in African American (AA) and Hispanic population $(29.3 \%$ vs $11.5 \%, p<0.01)$ and $(12.5 \%$ vs $7.3 \%, p<0.01)$ respectively. Patients with poor income status (0-25th percentile), had higher proportions of PEG tube placement $(36 \%$ vs $28.7 \%, \mathrm{p}<0.01)$. Similarly, those at high risk of frailty had higher PEG tube placement $(40.6 \%$ vs $16.6 \%, p<0.001)$. Table $1-A$ and $1 B$ summarizes various demographic and hospital factors as well as distribution of comorbidities in study population for the use of PEG tube. 
Table 1

A: Baseline characteristics of study population.

\begin{tabular}{|c|c|c|c|c|c|}
\hline & \multirow{2}{*}{\multicolumn{2}{|c|}{$\begin{array}{l}\text { No PEG tubes } \\
N=1,709,953\end{array}$}} & \multirow{2}{*}{\multicolumn{2}{|c|}{$\begin{array}{l}\text { PEG tube } \\
\mathrm{N}=35,075\end{array}$}} & \multirow[t]{3}{*}{$P$ value } \\
\hline & & & & & \\
\hline & $\%$ & $\mathrm{Cl}$ & $\%$ & $\mathrm{Cl}$ & \\
\hline Age & 83.4 & {$[83.4,83.5]$} & 82.3 & {$[82.1,82.5]$} & \\
\hline Female gender & 61.1 & {$[60.9,61.3]$} & 54.8 & {$[53.5,56.1]$} & $<0.001$ \\
\hline \multicolumn{6}{|l|}{ RACE category } \\
\hline White & 73.3 & {$[72.2,74.3]$} & 45.5 & {$[43.5,47.6]$} & $<0.001$ \\
\hline Black & 11.5 & {$[10.9,12.1]$} & 29.3 & {$[27.4,31.3]$} & \\
\hline Hispanic & 7.3 & {$[6.6,8.0]$} & 12.5 & {$[11.1,14.1]$} & \\
\hline \multicolumn{6}{|c|}{ Median household income national quartile for patient ZIP Code } \\
\hline $0-25$ th & 28.7 & {$[27.8,29.7]$} & 36 & {$[34.0,38.0]$} & $<0.001$ \\
\hline 26th to 50th & 25.2 & {$[24.4,26.0]$} & 22.6 & {$[21.2,24.1]$} & \\
\hline 51 st to 75 th & 24 & {$[23.3,24.7]$} & 21.6 & {$[20.2,23.1]$} & \\
\hline 76th to 100th & 22.1 & {$[21.0,23.2]$} & 19.7 & {$[18.1,21.5]$} & \\
\hline \multicolumn{6}{|l|}{ Insurance category } \\
\hline Medicare & 92.7 & {$[92.3,93.1]$} & 91.2 & {$[90.3,92.0]$} & $<0.001$ \\
\hline Medicaid & 1.2 & {$[1.1,1.3]$} & 3 & {$[2.5,3.6]$} & \\
\hline Private & 4.4 & {$[4.0,4.7]$} & 3.8 & {$[3.2,4.4]$} & \\
\hline \multicolumn{6}{|l|}{ Bed size of hospital } \\
\hline Small & 21.5 & {$[20.7,22.3]$} & 18.9 & {$[17.1,20.8]$} & 0.017 \\
\hline Medium & 30.8 & {$[29.9,31.6]$} & 31.1 & {$[28.9,33.4]$} & \\
\hline Large & 47.8 & {$[46.8,48.7]$} & 50 & {$[47.4,52.5]$} & \\
\hline \multicolumn{6}{|c|}{ Location/teaching status of hospital } \\
\hline Rural & 12.1 & {$[11.6,12.6]$} & 8.9 & {$[7.8,10.2]$} & $<0.001$ \\
\hline Urban nonteaching & 30.6 & {$[29.8,31.4]$} & 30.7 & {$[28.6,33.0]$} & \\
\hline Urban teaching & 57.3 & {$[56.4,58.3]$} & 60.3 & {$[57.9,62.7]$} & \\
\hline \multicolumn{6}{|l|}{ Region of hospital } \\
\hline Northeast & 19.8 & {$[19.0,20.6]$} & 18.8 & {$[16.7,21.3]$} & 0.001 \\
\hline
\end{tabular}




\begin{tabular}{|llllll|}
\hline & \multicolumn{2}{l}{ No PEG tubes } & \multicolumn{2}{ll}{ PEG tube } & P value \\
& N=1,709,953 & N=35,075 & \\
\hline Midwest or North Central & 22.1 & {$[21.3,22.9]$} & 18.7 & {$[16.9,20.6]$} & \\
\hline South & 40.8 & {$[39.8,41.7]$} & 42.4 & {$[40.0,44.9]$} & \\
\cline { 1 - 5 } West & 17.4 & {$[16.7,18.1]$} & 20 & {$[18.0,22.3]$} & \\
\hline Control/ownership of hospital & & & & \\
\hline Government, nonfederal & 9.7 & {$[9.1,10.3]$} & 10.1 & {$[8.8,11.6]$} & 0.001 \\
\hline Private, not-profit & 73.1 & {$[72.2,73.9]$} & 69.7 & {$[67.4,71.9]$} & \\
\hline Private, invest-own & 17.2 & {$[16.5,18.0]$} & 20.2 & {$[18.2,22.3]$} & \\
\hline
\end{tabular}


Table 1

B: Degree of frailty and prevalence of comorbidities among study population.

\begin{tabular}{|llllll|}
\hline & No PEG tube & \multicolumn{2}{ll}{ PEG tube } \\
& $\mathrm{N}=1,709,953$ & $\mathrm{~N}=35,075$ & \\
\hline & $\%$ & $95 \% \mathrm{Cl}$ & $\%$ & $95 \% \mathrm{Cl}$ & P value \\
\hline Degree of Frailty & & & & & \\
\hline Low risk & 11.7 & {$[11.5,11.9]$} & 2.2 & {$[1.9,2.6]$} & $<0.001$ \\
\hline Intermediate risk & 71.7 & {$[71.5,71.9]$} & 57.2 & {$[55.9,58.4]$} & \\
\hline High risk & 16.6 & {$[16.3,16.9]$} & 40.6 & {$[39.4,41.9]$} & \\
\hline Comorbidities & & & & & \\
\hline Deficiency anemias & 26.3 & {$[25.9,26.6]$} & 40.7 & {$[39.3,42.1]$} & $<0.001$ \\
\hline CHF & 28 & {$[27.7,28.3]$} & 27.7 & {$[26.5,28.9]$} & 0.569 \\
\hline Valvular disease & 11.4 & {$[11.2,11.6]$} & 6.1 & {$[5.5,6.8]$} & $<0.001$ \\
\hline COPD & 28.7 & {$[28.4,28.9]$} & 44.8 & {$[43.6,46.1]$} & $<0.001$ \\
\hline Diabetes mellitus & 32 & {$[31.7,32.3]$} & 40.6 & {$[39.3,41.9]$} & $<0.001$ \\
\hline Hypertension & 77 & {$[76.8,77.3]$} & 72.8 & {$[71.6,73.9]$} & $<0.001$ \\
\hline HLD & 42.3 & {$[41.9,42.8]$} & 34.7 & {$[33.4,36.0]$} & $<0.001$ \\
\hline Hypothyroidism & 22.5 & {$[22.3,22.7]$} & 18.2 & {$[17.2,19.2]$} & $<0.001$ \\
\hline Alcohol abuse & 1.5 & {$[1.5,1.6]$} & 0.7 & {$[0.5,0.9]$} & $<0.001$ \\
\hline Liver disease & 2.2 & {$[2.1,2.3]$} & 2 & {$[1.7,2.4]$} & 0.278 \\
\hline CKD & 27.3 & {$[27.0,27.6]$} & 23.7 & {$[22.6,24.8]$} & $<0.001$ \\
\hline Solid tumors & 4 & {$[4.0,4.1]$} & 3.7 & {$[3.3,4.2]$} & 0.191 \\
\hline Metastatic cancer & 1.6 & {$[1.6,1.7]$} & 1.5 & {$[1.2,1.8]$} & 0.295 \\
\hline PVD & 10.4 & {$[10.2,10.7]$} & 10.1 & {$[9.3,10.9]$} & 0.345 \\
\hline Psychoses & 4.7 & {$[4.5,4.9]$} & 5.9 & {$[5.3,6.5]$} & $<0.001$ \\
\hline Depression & 18.1 & {$[17.8,18.4]$} & 13.5 & {$[12.6,14.4]$} & $<0.001$ \\
\hline Atrial fibrillation & 30.1 & {$[29.8,30.3]$} & 28.1 & {$[26.9,29.3]$} & 0.001 \\
\hline CAD & 31 & {$[30.7,31.3]$} & 27.5 & {$[26.3,28.8]$} & $<0.001$ \\
\hline Tobacco use & 0.5 & {$[0.4,0.5]$} & 0.1 & {$[0.1,0.2]$} & $<0.001$ \\
\hline OSA & & {$[4.5,4.7]$} & 2.6 & {$[2.3,3.0]$} & $<0.001$ \\
\hline
\end{tabular}




\begin{tabular}{|c|c|c|c|c|c|}
\hline \multirow[b]{2}{*}{ Prior Stroke } & \multicolumn{2}{|c|}{$\begin{array}{l}\text { No PEG tube } \\
N=1,709,953\end{array}$} & \multicolumn{3}{|c|}{$\begin{array}{l}\text { PEG tube } \\
\mathrm{N}=35,075\end{array}$} \\
\hline & 16.5 & {$[16.3,16.8]$} & 22.9 & {$[21.8,23.9]$} & $<0.001$ \\
\hline DNI Status & 28.6 & {$[28.1,29.2]$} & 35.8 & {$[34.4,37.2]$} & $<0.001$ \\
\hline Lymphoma & 0.9 & {$[0.9,1.0]$} & 0.6 & {$[0.5,0.8]$} & 0.015 \\
\hline
\end{tabular}

Table 2

common reasons for admission among patients receiving gastrostomy

\begin{tabular}{|llll|}
\hline Rank & Count & ICD 10 code & Diagnosis \\
\hline 1 & 9060 & A419 & Sepsis, unspecified organism \\
\hline 2 & 3350 & J690 & Pneumonitis due to inhalation of food and vomit \\
\hline 3 & 1385 & N390 & Urinary tract infection, site not specified \\
\hline 4 & 1235 & J189 & Pneumonia, unspecified organism \\
\hline 5 & 830 & N179 & Acute kidney failure, unspecified \\
\hline 7 & 665 & Z431 & Encounter for attention to gastrostomy \\
\hline 8 & 350 & K922 & Gastrointestinal hemorrhage, unspecified \\
\hline 9 & 345 & A4151 & Acute respiratory failure with hypoxia \\
\hline 10 & 300 & E870 & Hyperosmolality and hypernatremia \\
\hline 11 & 295 & A4102 & Sepsis due to MRSA \\
\hline 12 & 280 & E860 & Dehydration \\
\hline 13 & 265 & A047 & Enterocolitis due to Clostridium difficile, not specified as recurrent \\
\hline 14 & 265 & A4189 & Other specified sepsis \\
\hline 15 & 260 & J441 & COPD with (acute) exacerbation \\
\hline
\end{tabular}


Table 3

Predictors for PEG tube placement.

\begin{tabular}{|c|c|c|c|c|}
\hline Category & Factor & aOR & $95 \% \mathrm{Cl}$ & $95 \% \mathrm{Cl}$ \\
\hline & Female gender & 0.78 & {$[0.74-0.82]$} & 0.00 \\
\hline \multicolumn{5}{|c|}{ Race Category } \\
\hline & White & 1 (Ref) & & \\
\hline & Black & 3.76 & [3.47-4.07] & 0.00 \\
\hline & Hispanic & 2.59 & [2.33-2.88] & 0.00 \\
\hline \multicolumn{5}{|c|}{ Insurance category } \\
\hline & Medicare & 1 (Ref) & & \\
\hline & Medicaid & 1.53 & {$[1.30-1.80]$} & 0.00 \\
\hline & Private & 0.82 & {$[0.71-0.95]$} & 0.01 \\
\hline \multicolumn{5}{|c|}{ Median household income national quartile for patient ZIP Code } \\
\hline & $0-25$ th & 1 (Ref) & & \\
\hline & 26th to 50th & 0.89 & {$[0.82-0.96]$} & 0.00 \\
\hline & 51st to 75th & 0.90 & {$[0.82-0.98]$} & 0.01 \\
\hline & 76th to 100th & 0.92 & {$[0.84-1.01]$} & 0.07 \\
\hline \multicolumn{5}{|c|}{ Bed size of hospital } \\
\hline & Small & 1 (Ref) & & \\
\hline & Medium & 1.06 & {$[0.95-1.18]$} & 0.30 \\
\hline & Large & 1.07 & {$[0.96-1.19]$} & 0.25 \\
\hline \multicolumn{5}{|c|}{ Location/teaching status of hospital } \\
\hline & Rural & 1 (Ref) & & \\
\hline & Urban nonteaching & 1.19 & {$[1.04-1.37]$} & 0.01 \\
\hline & Urban teaching & 1.12 & {$[0.97-1.28]$} & 0.12 \\
\hline \multicolumn{5}{|c|}{ Hospital region } \\
\hline & Northeast & 1 (Ref) & & \\
\hline & Mid-west or North Central & 0.82 & {$[0.71-0.95]$} & 0.01 \\
\hline & South & 0.94 & {$[0.82-1.08]$} & 0.38 \\
\hline & West & 0.99 & {$[0.85-1.15]$} & 0.87 \\
\hline
\end{tabular}




\begin{tabular}{|lllll|}
\hline Category & Factor & aOR & $95 \% \mathrm{Cl}$ & $95 \% \mathrm{Cl}$ \\
\hline Control/ownership of hospital & & & \\
\hline Government, nonfederal & 1 (Ref) & & \\
Private not-profit & 0.93 & {$[0.82-1.06]$} & 0.31 \\
\hline Private invest-own & 1.10 & {$[0.94-1.27]$} & 0.23 \\
\hline
\end{tabular}

On multivariable analysis, factors that correlated with higher risk of PEG tube placement included, AA or Hispanic versus White race; adjusted OR 3.76 (95\%Cl: 3.47-4.07) $\mathrm{p}<0.001$ and 2.59 (95\% Cl: 2.33-2.88) $p<0.001$ respectively, Medicaid insurance vs Medicare; adjusted OR $1.53(95 \% \mathrm{Cl} 1.30-1.80) \mathrm{p}<0.001$, Urban non-teaching hospital vs rural hospitals; adjusted OR $1.19(1.04-1.37]) p=0.01$. Lowest risk for PEG tube placement was observed among Private insurance vs Medicare; adjusted OR $0.82(95 \% \mathrm{Cl}$ : $0.71-0.95) p=0.01$, hospital location within mid-west or North compared to north east; adjusted OR 0.82 $(95 \% \mathrm{Cl}: 0.71-0.95) \mathrm{p}=0.01$. Hospital ownership and bed size had no significant impact on utilization of PEG tube.

\section{Discussion}

The main focus of this study is on racial and socioeconomic differences in percutaneous endoscopic gastrostomy (PEG) tube placement among patients aged 70 and above who lived with dementia. Despite the strong evidence; against using enteral feeding in frail, elderly patients with dementia owing to unproven survival benefit, we found that $40.6 \%$ of the high-risk frail elderly patients hospitalized during the year 2016 in the united states received PEG tube ${ }^{[13]}$.

Compared to Caucasians, the incidence of PEG tube placement is higher in African American and Hispanic populations, and highest among people who belong to low-income backgrounds who are insured through Medicaid. To date, the explanation for these medical choices is unclear but proposed to be due to availability of more advanced directives and end of life goals planning in Caucasians as compared to African Americans ${ }^{[15,16]}$.

The racial and ethnic differences in end of life care for dementia patients have been reported for many years in the United States. Previous studies reported that Caucasian patients are more likely to have an insight about DNR (do not resuscitate) orders and have advanced care directives compared to their African American counterparts ${ }^{[17,18]}$. One of the reasons for this difference is thought to be mistrust amongst the African American population for physicians and healthcare personal or policy generally $[19,20,21]$. The major reason of this mistrust is proposed to be higher numbers of AA population being enrolled as subjects for research and investigation without being provided with accurate insight of the consequences. Particularly in older population, distrust is attributed to the complexity and ambiguity of US healthcare system specifically for physician-patient encounters. Furthermore, vulnerability of healthcare delivery adds to mistrust among these patients. 
In terms of sex differences, previous epidemiological studies discovered a higher incidence of PEG tube insertions in men following an episode of stroke. In a study involving 36,109 patients who received PEG tube placement after a stroke, Faigle and colleagues found that the proportion of PEG tube placement was higher in men than in women $(50.0 \%$ vs $39.2 \%, p<0.001){ }^{[22]}$. Our study is consistent with these findings, as males had significantly higher PEG tube placements than women.

Of note, insurance is an important component of healthcare delivery in the United States and has a significant impact on quality of life of a person carrying a diagnosis of dementia. It not only affects the patient but also has an impact on their families and treatment outcomes to a great extent. A study by Mitchell and colleagues in 2004 revealed that residents in long-term care homes having PEG tube generated a higher daily reimbursement from Medicaid and required less nursing home care. Alternatively, Medicare offered less reimbursement ${ }^{[23]}$. Patients having low income (between 1-25th percentile and first quartile) had the highest incidence of PEG tube insertions as compared to patients who had higher incomes (Table 1-A, Fig. 4).

With respect to healthcare settings, we found out higher rate of PEG tube insertions in non-teaching hospitals, owing to time constraints, number of physicians, and patient volume. As expected, compared to rural hospitals, urban non-teaching hospitals had a higher incidence of PEG tube placements while no significant difference was noted on rate of PEG tube placement in teaching vs rural hospitals. In a survey conducted by Teno and colleagues on 486 family members of patients with dementia, the investigating team found out that in $71.6 \%$ of the cases, there was no reported decision about feeding tubes. Of respondents whose family members had feeding tubes, $13.7 \%$ stated that there was no discussion about insertion of a tube and $41.6 \%$ reported a discussion that was shorter than 15 minutes ${ }^{[24]}$. This suggested that involving family members in the decision-making process and explaining the risks and benefits of PEG tube insertion clearly can help prevent unnecessary insertions of feeding tubes that can also lead to complications later on .

On a relevant note, studies have shown no appreciable difference in terms of patient recovery or mortality rates in teaching vs non-teaching hospitals ${ }^{[25]}$. The capacity of the hospital in terms of size and beds, was not relevant to the number of patients receiving PEG tubes. Interestingly, the hospitals in the Northeast had a higher incidence of PEG tube insertions when compared with other regions (i.e., Mid-West or North-Central) [26]. The reason for these regional differences is unknown, as there was no significant difference between government-run and private hospitals in terms of the number of PEG tube placements.

Despite the evidence against the use of PEG tube insertions among elderly frail patients with dementia, PEG tubes are still being placed in order to improve nutrition in this sub-stratum of the population. We have noted several reasons to explain this trend. Primarily, physicians lack ample amount of time to explain the risks and benefits to family members (as proxy decision makers), and also the mortality rates, side-effects, and harms ${ }^{[14,24]}$. 
The advantage of this study is that it includes a large population sample representative of the general inpatient population of the United States. The main limitation of this study is that the type and stage of dementia is unknown. There is no stratification of dementia into early or late stages.

\section{Conclusion}

Despite known adverse effects of PEG tube placement in frail cognitively older adults, PEG tube placement remains very prevalent in older males and African American population. Understanding the cultural differences and education about end of life care at a community level to reduce PEG tube placement in frail cognitively impaired elderly population. The higher incidence of PEG tube placement in urban non-teaching hospitals warrants quality improvement in these hospitals to help improve outcomes.

\section{Abbreviations}

DNR

Do Not Resuscitate

$A A$

African-American

PEG

Percutaneous Endoscopic Gastrostomy

NIS-HCUP

National Inpatient Sample-Healthcare Utilization Project

\section{Declarations}

This abstract was accepted to be presented at "American Geriatrics Society" in 2020.

\section{Ethics Approval and Consent to Participate}

The HCUP databases are consistent with the definition of limited data sets under the HIPAA Privacy Rule and contain no direct patient identifiers. HCUP Data Use Agreement (DUA) training and a signed DUA are required to purchase and/or use the HCUP databases. Institutional review board (IRB) approval was not required for this study as HCUP-NIS data is publicly available without individual identifiers.

\section{Consent for publication}




\section{Availability of data and material}

The datasets generated and/or analyzed during the current study are available in the HCUP-NIS database https://www.hcup-us.ahrq.gov/tech_assist/faq.jsp.

\section{Competing interests}

All authors declare no conflict of interest in preparing this manuscript.

\section{Funding}

No funding or grant was obtained for this study.

\section{Authors' contributions}

TK: Conceptualization, study design, analysis and interpretation of data, writing and editing the manuscript; AA: Data analysis and interpretation, editing of manuscript; AN: writing and editing; MS: Data Curation, Methodology and Analysis, PP: Supervision, final reviewing and editing.

All authors have read and have approved the manuscript.

\section{Acknowledgements}

N/A

\section{References}

1. Hebert LE, Weuve J, Scherr PA, Evans DA. Alzheimer disease in the United States (2010-2050) estimated using the 2010 census. Neurology. 2013;80(19):1778-83. doi:10.1212/WNL.0b013e31828726f5.

2. Hebert LE, Scherr PA, Bienias JL, Bennett DA, Evans DA. Alzheimer Disease in the US Population: Prevalence Estimates Using the 2000 Census. Arch Neurol. 2003;60(8):1119-22. doi:10.1001/archneur.60.8.1119.

3. Gillick $M$. When the nursing home resident with advanced dementia stops eating: what is the medical director to do? J Am Med Dir Assoc. 2001;2(5):259-63. 
4. Mitchell SL, Teno JM, Kiely DK, et al. The clinical course of advanced dementia. N Engl J Med. 2009;361(16):1529-38. doi:10.1056/NEJMoa0902234.

5. Ayman AR, Khoury T, Cohen J, et al. PEG Insertion in Patients With Dementia Does Not Improve Nutritional Status and Has Worse Outcomes as Compared With PEG Insertion for Other Indications. J Clin Gastroenterol. 2017;51(5):417-20. doi:10.1097/MCG.0000000000000624.

6. Abuksis G, Mor M, Plaut S, Fraser G, Niv Y. Outcome of percutaneous endoscopic gastrostomy (PEG): comparison of two policies in a 4-year experience. Clin Nutr. 2004;23(3):341-6. doi:10.1016/j.clnu.2003.08.001.

7. Ticinesi A, Nouvenne A, Lauretani F, et al. Survival in older adults with dementia and eating problems: To PEG or not to PEG? Clin Nutr. 2016;35(6):1512-6. doi:10.1016/j.clnu.2016.04.001.

8. Kuo S, Rhodes RL, Mitchell SL, Mor V, Teno JM. Natural history of feeding-tube use in nursing home residents with advanced dementia. J Am Med Dir Assoc. 2009;10(4):264-70. doi:10.1016/j.jamda.2008.10.010.

9. Barone M, Viggiani MT, Amoruso A, et al. Influence of age and type of underlying disease on complications related to home enteral nutrition: a single Italian center experience. JPEN J Parenter Enteral Nutr. 2014;38(8):991-5. doi:10.1177/0148607113498422.

10. Cervo FA, Bryan L, Farber S. To PEG or not to PEG: a review of evidence for placing feeding tubes in advanced dementia and the decision-making process. Geriatrics. 2006;61(6):30-5.

11. Gieniusz M, Sinvani L, Kozikowski A, et al. Percutaneous Feeding Tubes in Individuals with Advanced Dementia: Are Physicians “Choosing Wisely"? J Am Geriatr Soc. 2018;66(1):64-9. doi:10.1111/jgs.15125.

12. American Geriatrics. Society feeding tubes in advanced dementia position statement. J Am Geriatr Soc. 2014;62(8):1590-3. doi:10.1111/jgs.12924.

13. Alagiakrishnan K, Bhanji RA, Kurian M. Evaluation and management of oropharyngeal dysphagia in different types of dementia: a systematic review. Arch Gerontol Geriatr. 2013;56(1):1-9. doi:10.1016/j.archger.2012.04.011.

14. Komiya K, Usagawa Y, Kadota J-I, Ikegami N. Decreasing Use of Percutaneous Endoscopic Gastrostomy Tube Feeding in Japan. J Am Geriatr Soc. 2018;66(7):1388-91. doi:10.1111/jgs.15386.

15. Perkins HS, Geppert CMA, Gonzales A, Cortez JD, Hazuda HP. Cross-cultural similarities and differences in attitudes about advance care planning. J Gen Intern Med. 2002;17(1):48-57. doi:10.1046/j.1525-1497.2002.01032.x.

16. Zaide GB, Pekmezaris R, Nouryan CN, et al. Ethnicity, race, and advance directives in an inpatient palliative care consultation service. Palliat Support Care. 2013;11(1):5-11. doi:10.1017/S1478951512000417.

17. Shepardson LB, Gordon HS, Ibrahim SA, Harper DL, Rosenthal GE. Racial variation in the use of donot-resuscitate orders. J Gen Intern Med. 1999;14(1):15-20. doi:10.1046/j.1525-1497.1999.00275.x.

18. Mack JW, Paulk ME, Viswanath K, Prigerson HG. Racial disparities in the outcomes of communication on medical care received near death. Arch Intern Med. 2010;170(17):1533-40. 
doi:10.1001/archinternmed.2010.322.

19. Kennedy BR, Mathis CC, Woods AK. African Americans and their distrust of the health care system: healthcare for diverse populations. J Cult Divers. 2007;14(2):56-60.

20. Mascarenhas OAJ, Cardozo LJ, Afonso NM, et al. Hypothesized predictors of patient-physician trust and distrust in the elderly: implications for health and disease management. Clin Interv Aging. 2006;1(2):175-88. doi:10.2147/ciia.2006.1.2.175.

21. Dunlop DD, Manheim LM, Song J, Chang RW. Gender and ethnic/racial disparities in health care utilization among older adults. J Gerontol B Psychol Sci Soc Sci. 2002;57(4):221-33. doi:10.1093/geronb/57.4.s221.

22. Faigle R, Bahouth MN, Urrutia VC, Gottesman RF. Racial and Socioeconomic Disparities in Gastrostomy Tube Placement After Intracerebral Hemorrhage in the United States. Stroke. 2016;47(4):964-70. doi:10.1161/STROKEAHA.115.011712.

23. Mitchell SL, Buchanan JL, Littlehale S, Hamel MB. Tube-feeding versus hand-feeding nursing home residents with advanced dementia: a cost comparison. J Am Med Dir Assoc. 2004;5(2 Suppl):22-9. doi:10.1097/01.JAM.0000043421.46230.0E.

24. Teno JM, Mitchell SL, Kuo SK, et al. Decision-making and outcomes of feeding tube insertion: a fivestate study. J Am Geriatr Soc. 2011;59(5):881-6. doi:10.1111/j.1532-5415.2011.03385.x.

25. Papanikolaou PN, Christidi GD, loannidis JPA. Patient outcomes with teaching versus nonteaching healthcare: a systematic review. PLoS Med. 2006;3(9):e341. doi:10.1371/journal.pmed.0030341.

26. Mendiratta P, Tilford JM, Prodhan P, Curseen K, Azhar G, Wei JY. Trends in percutaneous endoscopic gastrostomy placement in the elderly from 1993 to 2003. Am J Alzheimers Dis Other Demen. 2012;27(8):609-13. doi:10.1177/1533317512460563.

\section{Figures}




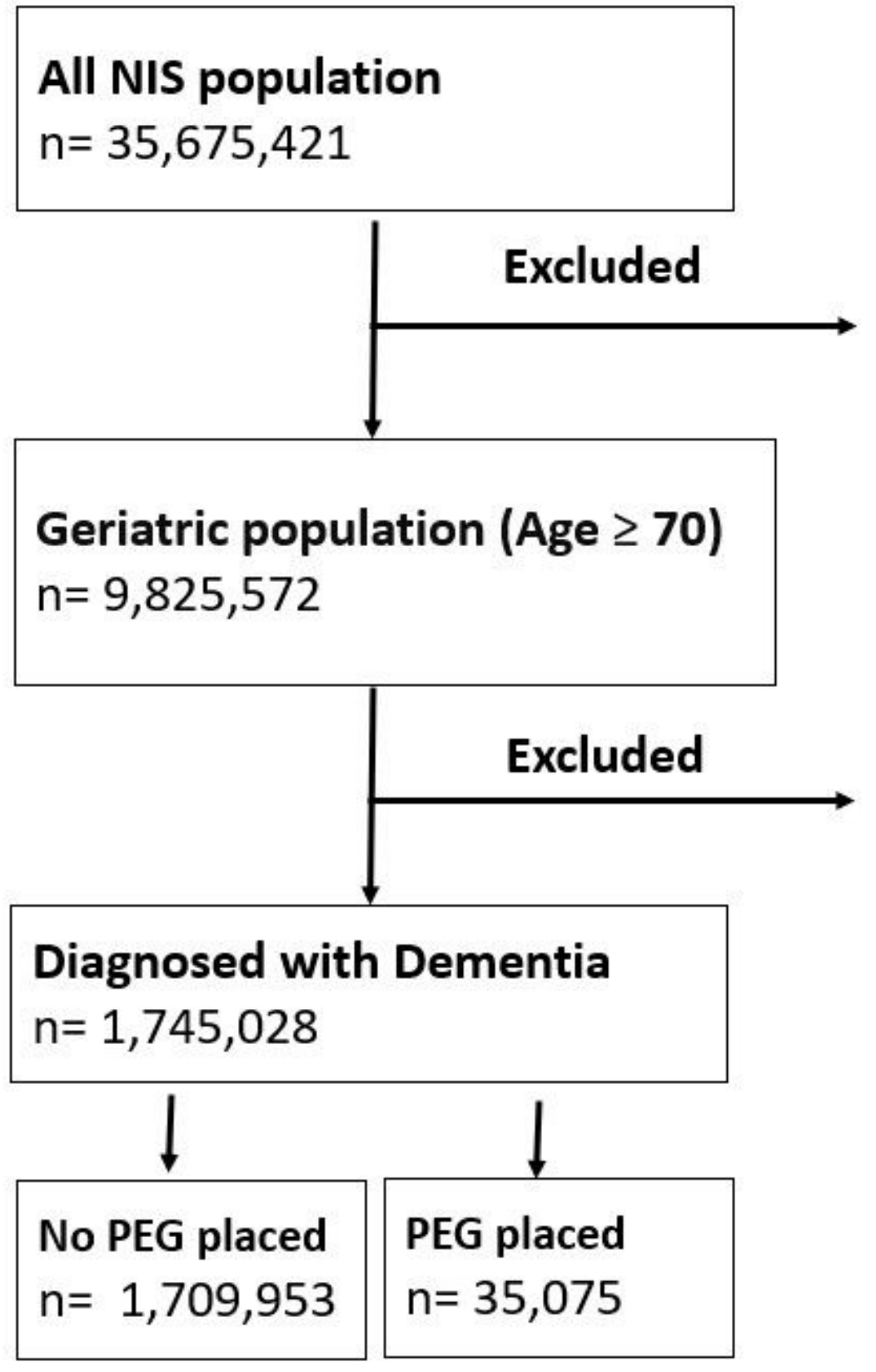

Aged $<70$ $n=25,849,849$

No dementia

$n=8,080,544$

Figure 1

Patient selection algorithm 


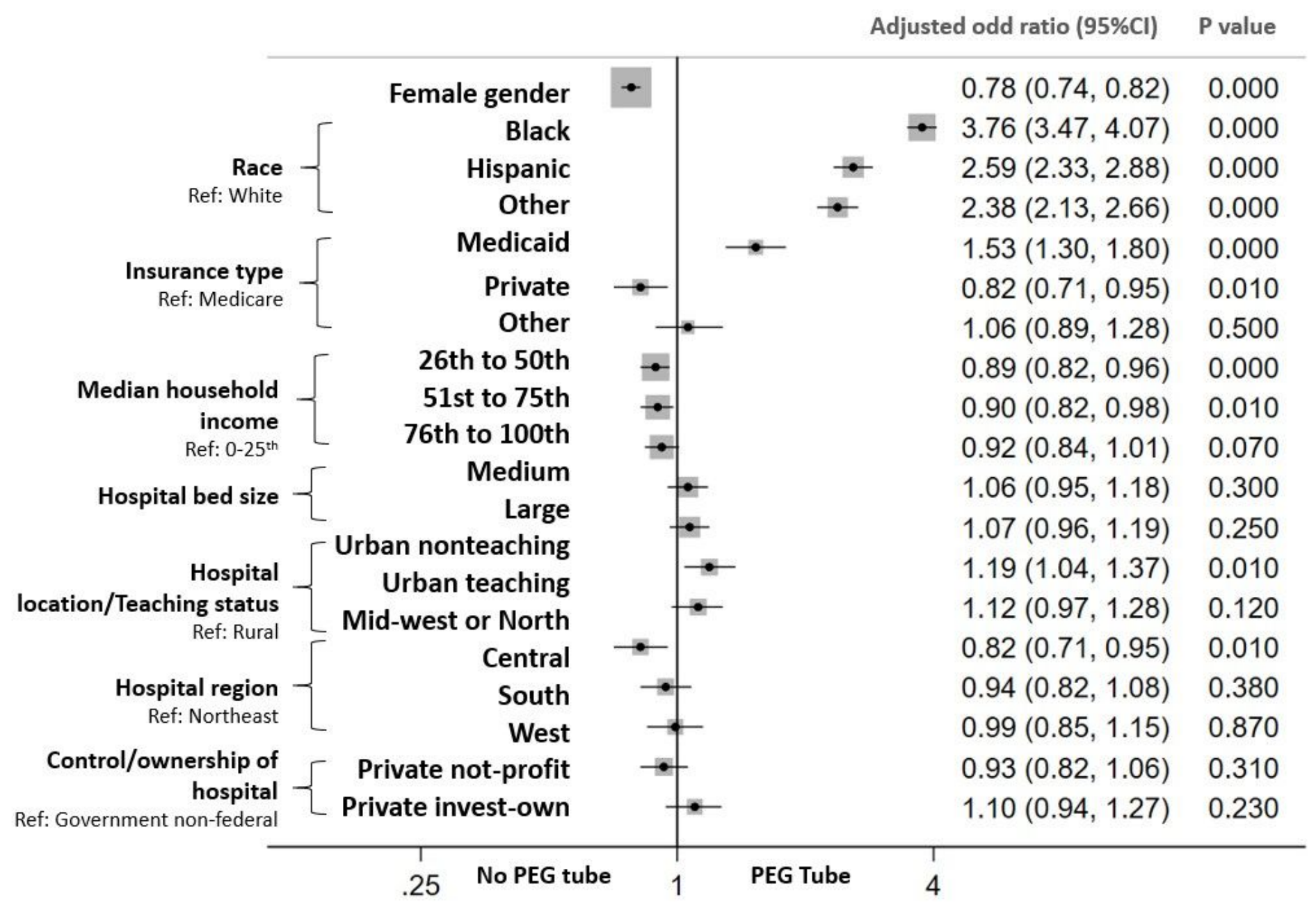

Figure 2

Forest plot summarizing the predictors of PEG tube placement according to race, insurance type, household income and hospital settings

\section{Supplementary Files}

This is a list of supplementary files associated with this preprint. Click to download.

- STROBEchecklistcompleted.doc 